\title{
Scheduling of an assembly process of a chosen technical mean using the critical chain approach
}

\author{
Iwona Paprocka ${ }^{1, *}$, Aleksander Gwiazda ${ }^{1}$, and Magdalena Bączkowicz ${ }^{1}$ \\ ${ }^{1}$ Silesian University of Technology, Faculty of Mechanical Engineering, Konarskiego 18A Str., 44- \\ 100 Gliwice, Poland
}

\begin{abstract}
In the work is presented the CCPM (Critical Chain Project Management) method that differs from other network approaches. The differences are related with: the scheduling process, with restrictions of the project that are taken into account and with the time buffers allowing avoiding delays in realized tasks. Each project should be such organized to effectively achieve the previously assumed goals. The paper presents all the steps involved with utilization the CCPM method for determining the schedule of an assembly process of a mining shearer machine. It is presented the elaboration of the network of tasks and preparation the process schedule. It is also realized the resource optimization and the safety buffers introduction.
\end{abstract}

\section{Introduction}

The Critical Chain Project Management (CCPM) is one of the methods of project management using network planning. This method is called also as the Critical Chain method. It is derived from the Theory of Constraints (ToC) and nowadays it is the main tool used in ToC. CCPM method was developed in 1997 by E. Goldratt and was presented in the book "Critical Chain". It could be described as a method of planning and project management, which is focused on resources needed to perform planned tasks $[1,2]$. This method differs from other methods based on network planning and using the idea of a critical path. The major difference is that the CCPM uses an alternative analysis of this critical path, called the critical chain. It is distinguished by the optimization of resources included in the critical chain and no in the critical path. Additionally, during project managing using CCPM, are used new system components that improve the planning procedure. These additional components are: Project Buffer, Feeding Buffer and Resource Buffer [3]. These buffers are used in project planning as safety buffers. The main objective of CCPM is to shorten the duration of a project and simultaneously balancing utilized resources. This in a consequence leads to costs reducing and increasing probability of the project execution on required time.

The analysed method is partly heuristic. It is based largely on the Continuous Path Method (CPM) and certain properties of the distribution of the sum of random variables as

*Corresponding author : iwona.wosik@polsl.pl 
well as on some psychological behaviour, to which people are subjected [3]. Project management using CCPM is very advantageous because it leads to reducing the multitasking of resources, to eliminate conflicts related with the allocation of resources, eliminating a common practice starting job at the last possible moment (so called Student's Syndrome). Moreover its application allows preventing artificial increasing the amount of work needed to complete the scheduled time (so called Parkinson's Law). Additionally CCPM allows utilize the so called relay-race effect (systematic use of the time saved on individual tasks), more efficiently controlling projects realization (through monitoring the buffers utilization). Finally utilization of this approach lets to avoid the negative influence of the Murphy right (anything that can go wrong will go wrong). The loss of time and resources is mainly due to waste of these factors. Critical Chain Project Management allows avoiding loss of time and loss of resources. This is why projects are implemented about $20-30 \%$ faster, and the risk of delays is significantly reduced. In the end projects are cheaper, and the risk of cost overruns is significantly reduced $[4,5,6]$.

Not only the balance of resources and the introduction of buffers are factors that distinguish CCPM method from traditional ones. The factors of CCPM are also times of tasks that are reduced from conservative estimates to realistic ones. The next factor is the moment of beginning the given task. All activities associated with this task begin as late as possible in accordance with the ALAP principle (As Late As Possible) $[7,8,9]$.

\section{Characteristics of the analysed production process}

In this chapter are described all the steps considered with CCPM utilization for determining the schedule of manufacturing process of a mining shearer loader (Figure 1). The analysis begins with creating the network of dependences, through schedule creating, resource optimization to the introduction of safety buffers. The production process of a shearer loader is generally a one piece one. The whole shearer loader is assembled on one stand $[10,11]$ using specific materials $[12,13,14]$.

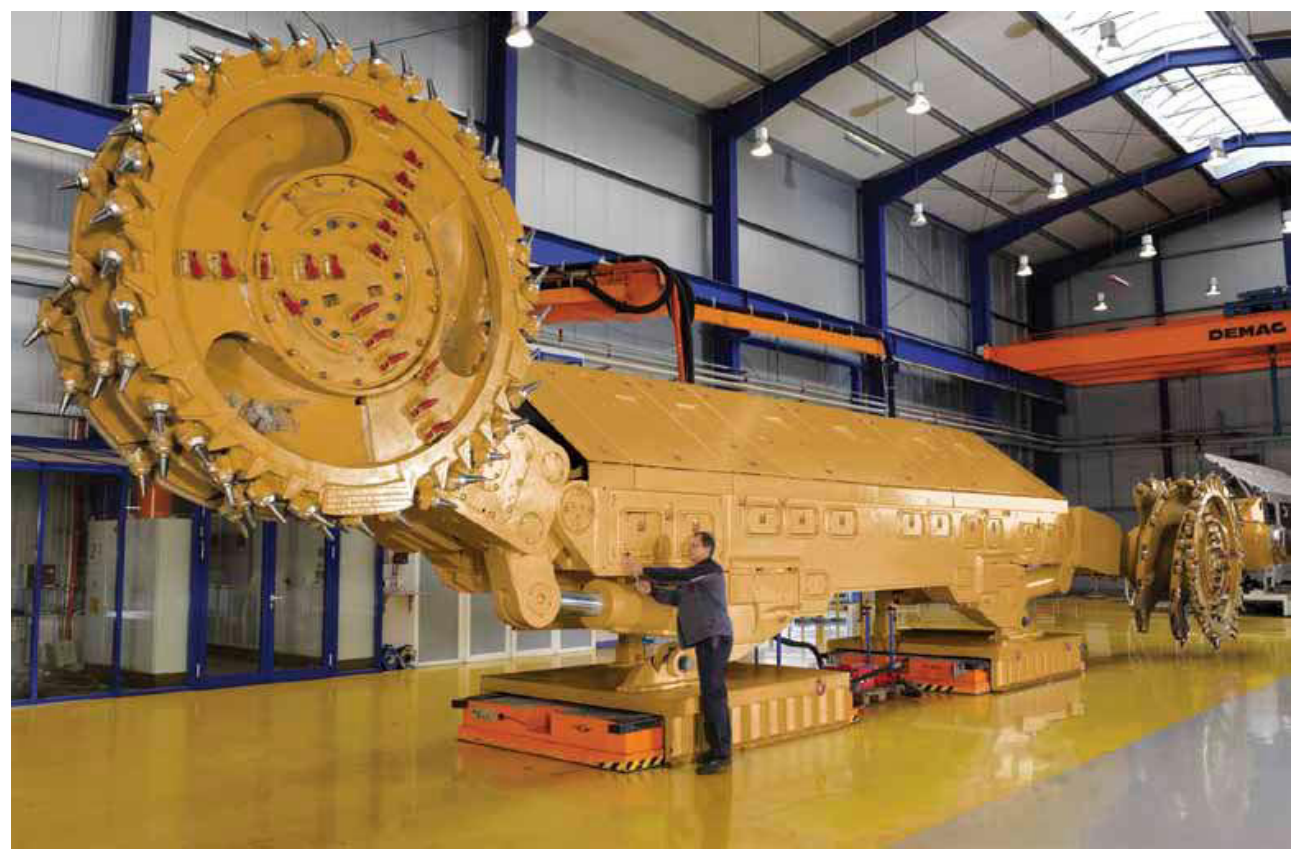

Fig. 1. Mining shearer loader [9]. 
All components and subassembly are delivered to this stand. It is a long process. This was the main reason due to which it was decided to use the CCPM approach. It was realized as a special technological project. The project consists of 17 tasks, 9 of which are manufacturing type tasks, and the remaining 8 are the tasks of assembly type (Table 1). To each task is assigned its duration and the person, who is responsible for it.

Table 1. Characterisation of realized tasks.

\begin{tabular}{|c|c|c|c|c|c|c|}
\hline $\begin{array}{c}\text { Task } \\
\text { No }\end{array}$ & $\begin{array}{l}\text { Task } \\
\text { code }\end{array}$ & $\begin{array}{l}\text { Task } \\
\text { type }\end{array}$ & $\begin{array}{c}\text { Task name } \\
\text { (in parenthesis number of } \\
\text { subassemblies) }\end{array}$ & $\begin{array}{l}\text { Preceding } \\
\text { task No }\end{array}$ & $\begin{array}{c}\text { Task } \\
\text { duration } \\
\text { [days] }\end{array}$ & $\begin{array}{l}\text { Worker } \\
\text { symbol }\end{array}$ \\
\hline 1. & $\mathbf{A}$ & \multirow{9}{*}{ 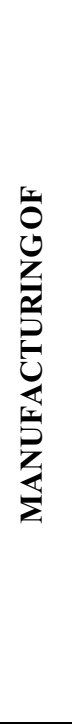 } & the ranging arm & - & 15 & $\mathrm{a}$ \\
\hline 2. & B & & the loader & - & 35 & b \\
\hline 3. & $\mathbf{C}$ & & the cutting system & - & 35 & $\mathrm{~g}$ \\
\hline 4. & D & & the cutting head & - & 20 & $\mathrm{~h}$ \\
\hline 5. & $\mathbf{E}$ & & $\begin{array}{l}\text { the transmission of the feed drive } \\
\text { (2) }\end{array}$ & - & 45 & e \\
\hline 6. & $\mathbf{F}$ & & the drive system & - & 45 & $\mathrm{c}$ \\
\hline 7. & G & & the electric drive (2) & - & 75 & $\mathrm{~b}$ \\
\hline 8. & H & & $\begin{array}{l}\text { the transforming-converting unit } \\
\text { BTP-1 }\end{array}$ & - & 70 & $\mathrm{f}$ \\
\hline 9. & I & & $\begin{array}{l}\text { the block of electric devices } \\
\text { BAE-18 (2) }\end{array}$ & - & 15 & $\mathrm{~g}$ \\
\hline 10. & $\mathbf{J}$ & \multirow{8}{*}{$\begin{array}{l}\frac{1}{0} \\
\frac{\lambda}{3} \\
\frac{1}{2} \\
\frac{1}{2} \\
\frac{1}{2}\end{array}$} & $\begin{array}{l}\text { the cutting head and the cutting } \\
\text { system }\end{array}$ & C, D & 30 & $\mathrm{a}$ \\
\hline 11. & K & & $\begin{array}{l}\text { the ranging arm with the loader } \\
\text { and subassembly obtained in the } \\
\text { task } \mathbf{1 0}\end{array}$ & A, B, J & 30 & $\mathrm{~h}$ \\
\hline 12. & $\mathbf{L}$ & & $\begin{array}{l}\text { the drive system with the electric } \\
\text { drive (2) }\end{array}$ & $\mathrm{F}, \mathrm{G}$ & 20 & e \\
\hline 13. & $\mathbf{L}$ & & $\begin{array}{l}\text { the transmission of the feed drive } \\
\text { and the subassembly obtained in } \\
\text { the task } \mathbf{1 2}\end{array}$ & E, L & 35 & d \\
\hline 14. & M & & $\begin{array}{l}\text { the subassembly obtained in the } \\
\text { task } \mathbf{1 3} \text { and the transforming- } \\
\text { converting unit BTP-1 }\end{array}$ & $Ł, H$ & 25 & $\mathrm{c}$ \\
\hline 15. & $\mathbf{N}$ & & $\begin{array}{l}\text { the subassembly obtained in the } \\
\text { task } \mathbf{1 3} \text { and the block of electric } \\
\text { devices BAE-18 }\end{array}$ & $Ł, I$ & 15 & c \\
\hline 16. & $\mathbf{O}$ & & $14+15$ & $\mathrm{M}, \mathrm{N}$ & 15 & $\mathrm{~d}$ \\
\hline 17. & $\mathbf{P}$ & & $11+16$ & $\mathrm{~K}, \mathrm{O}$ & 10 & e \\
\hline
\end{tabular}


In order to determine the critical path it was elaborated a network of dependencies between particular tasks that should be realized. This network is presented in Figure 2. On the basis of the elaborated network of dependences it was determined the tasks that are noncritical and the ones that are critical. The sequence of tasks within the critical path is marked in red, while the remaining tasks are marked in blue. According to the established relationships between the tasks and their duration it was also determined the duration of the entire project, which is 175 days. It should be mentioned that numbers of some subassemblies of the shearer loader are odd. This concern particularly to these related with ranging arms. This fact is indicated in the table by the symbol (2). Also some tasks are defined by determining number of task, in which are assembled used subassemblies.

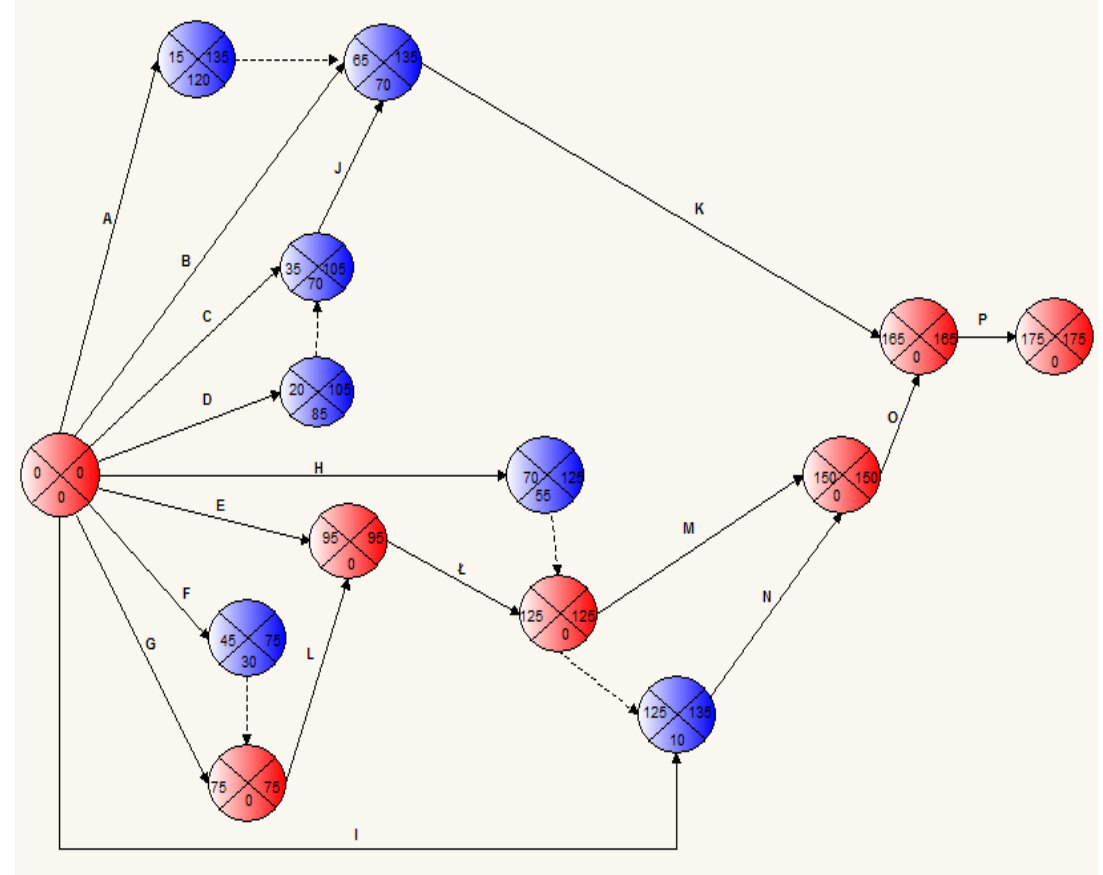

Fig. 2. Network of dependences for the project of a shearer loader manufacturing.

In the diagram above the continuous arrow means a real task and dashed one - an apparent one. The used symbols are presented in Figure 3. In the symbol also are determined three different factors characterising realization of particular tasks. The time $t_{i}$ means the earliest moment of the task realization, $\mathrm{T}_{\mathrm{i}}$ - the latest moment of the task realization and $\mathrm{L}_{\mathrm{i}}$ - time reserve for the task realization.

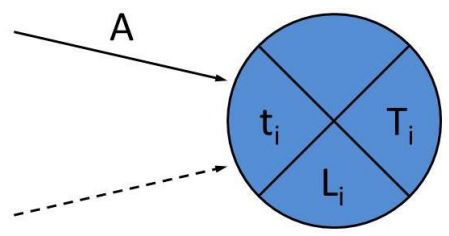

Fig. 3. Symbols used in the network of dependences.

In the next chapter is presented the elaboration of the schedule for the presented project of mining shearer loader manufacturing. The schedule is based on the presented network of dependences but also includes the priority rules. 


\section{Schedule elaboration}

As it was stated the next step is to determine the schedule according to the ALAP principle, that means starting with the last and ending with the initial task. In such elaborated schedule tasks are initiated as late as possible. In order to illustrate the difference between the scheduling from the beginning task and from the last one there have been elaborated two schedules. The first one is elaborated according the ASAP (As Soon As Possible) principle. It is presented in Figure 4. The second schedule is elaborated according to the ALAP principle and is presented in Figure 5.For elaboration the schedules was utilized the program Gantt Project. Below are presented windows of this program. Elaborating the presented schedules it was taken into account the durations of the project tasks described in Table 1. In this schedules also were considered days off, weekends and public holidays. It was done to make more real the elaborated schedules. It was also assumed a hypothetical date of completion of the project. The time unit in the schedule is one week.

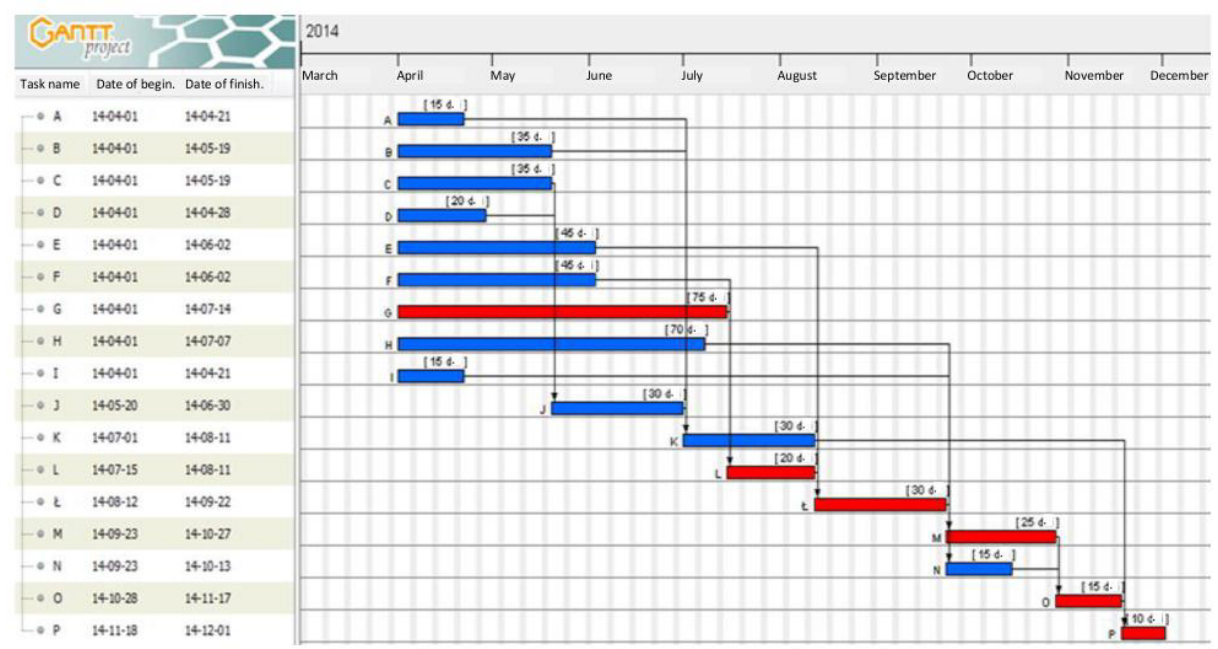

Fig. 4. Schedule elaborated according the ASAP principle (d. - days).

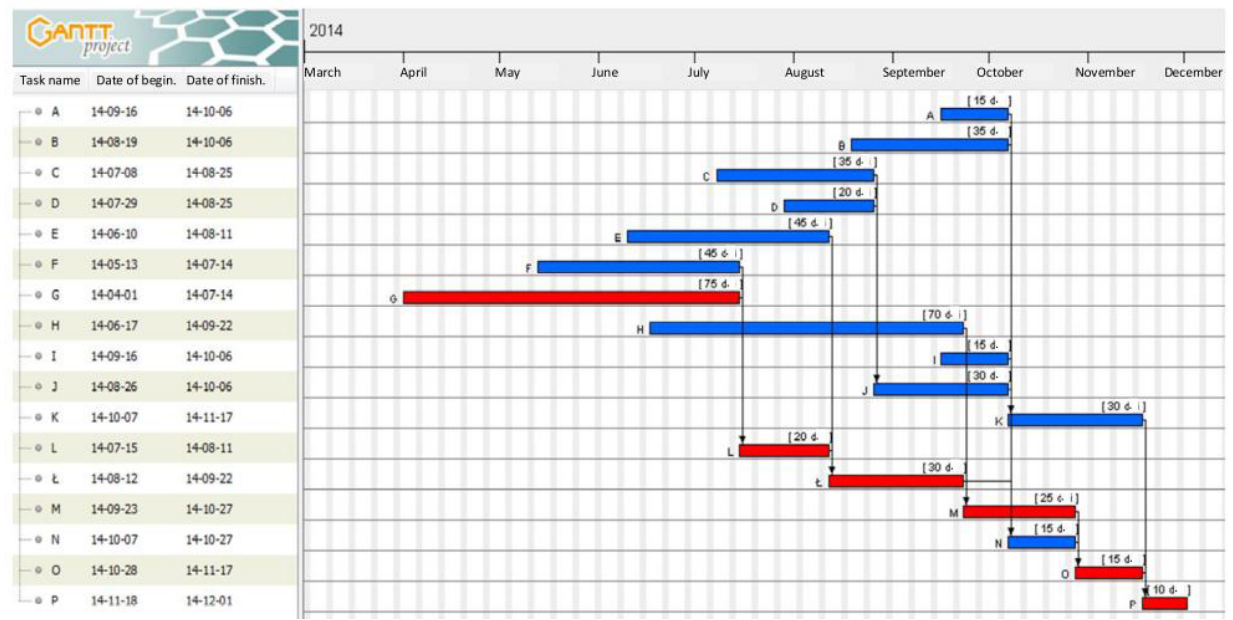

Fig. 5. Schedule elaborated according the ALAP principle (d. - days). 
Critical chain is the longest sequence of tasks, together with balanced resources. To determine the critical chain one should take into account both the interdependencies between tasks, and dependences concerning the availability of resources. In the case of this project the most considered problem is the availability of workers performing specific design tasks (as a specific type of scarce resources). For this purpose it was built the schedule with the adopted time unit (one week), presented in Figure 6. The analysis of this schedule allows determining resource conflicts in the elaborated plan (marked in yellow). For example, it was identified the resource conflict between tasks E and L, as at the same time the same employee was assigned to perform work in these two tasks simultaneously. Conflicts were also observed between tasks $\mathrm{M}$ and $\mathrm{N}$ as well as between $\mathrm{A}$ and $\mathrm{J}$.

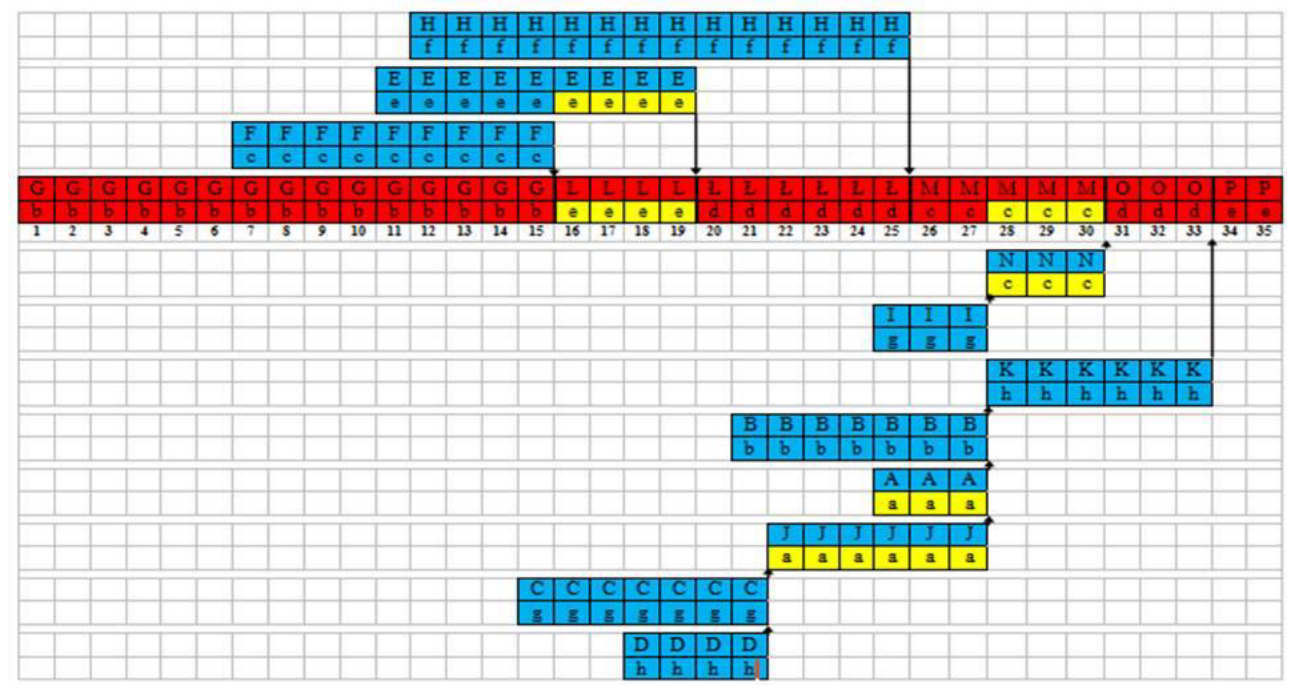

Fig. 6. Illustration of resources conflict.

In order to solve resource conflicts, one should balance the order of the tasks of the project. The schedule after the conflicts elimination, and thus the determination of the critical chain, is shown in Figure 7 (ordered resources are marked in green).

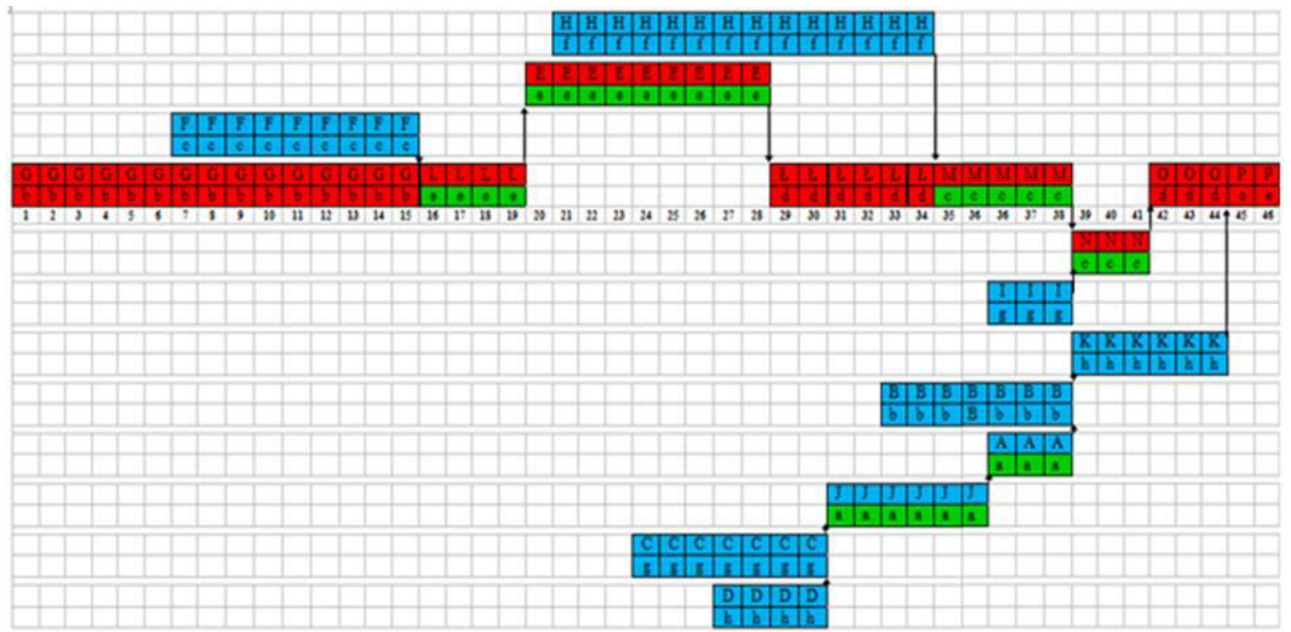

Fig. 7. New schedule according CCPM. 
Determination of the order of tasks, which were the source of the conflict, does not affect the length of the duration of the whole project. This is why it was not needed to assign them special, additional priorities. Including these dependences in the schedule elaborated according the ALAP principle, one receives the schedule that is presented in Figure 8. It shows the sequence of re-ordered tasks taking into account the problems considered scares resources. The critical chain is marked in red. Other tasks (non-critical) are marked in blue.

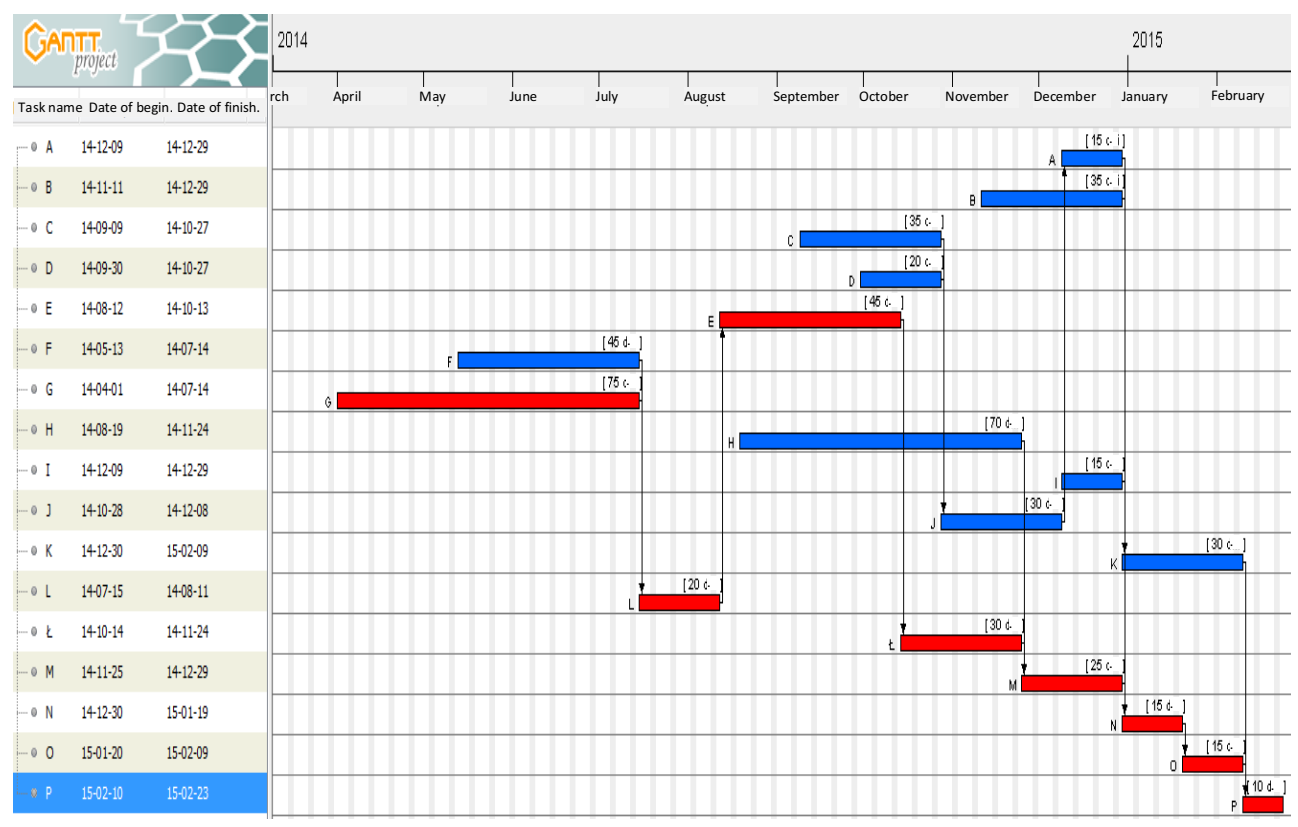

Fig. 8. Schedule with the critical chain (d. - days).

The introduction of new dependence taking into account the availability of resources resulted in extending the duration of the entire project. The duration of the project was extended from initial eight months to eleven. It gives another three months but currently the project is scheduled without hidden resources conflicts.

\section{Conclusions}

Basing on the conducted investigations one could state that CCPM application is characterised by many advantages and raises a number of problems. Firstly, elaboration of a network of dependences, for project tasks of different types (manufacturing and assembly ones) required modification because of the resource conflicts. It was introduced one initial task for manufacturing tasks having no preceding task. At this stage, the duration of the project was 175 days (approximately 8 moths). Secondly, by elaborating both the schedule according the ASAP principle and the ALAP one, it was possible to illustrate the difference between the CCPM approach, and other methods of network planning like CPM/COST, CPM/PERT etc., as these methods function only according the ASAP principle. So only CCPM allows taking into consideration the problem of resources conflicts. In the presented analysis, three resources conflict related with ordering different tasks to the same staff at the same time were detected. Using the ASAP principle it is probable that this conflicts would be detected during the realization of the project and resulted in unplanned project rescheduling. Thirdly, to avoid conflict one should optimize the primary schedule and to 
determine the critical chain that allows scheduling both tasks and resources. However such approach results in extending the duration of the project (up to 230 days) but on the other hand the optimized schedule is more realistic.

This work has shown the importance of the selection of the appropriate method of project management $[15,16,17]$. On it depends whether the achievement of the project objective will be realized without disturbances and breaks or it would be implemented with the emergency attempts to resolve conflicts considered scares resource and often convened ad hoc meetings (so called task forces). It is also important to resolve the problem of data analysis $[18,19]$.

CCPM is the only method that focuses not only on the reduction of time to minimize project costs, but also enables the optimization of resources. In comparison to traditional project management techniques it is a method which overcomes the waste of time and financial resources especially.

\section{References}

1. E. M. Goldratt, Theory of Constraints (The North River Press, Great Barrington, 1999)

2. E. M. Goldratt, Critical Chain (The North River Press, Great Barrington, 2002)

3. L. P. Leach, Critical Chain Project Management (Artech House, London, 2004)

4. J. M. Antill, R. W. Woodhead, Critical Path Methods in Construction Practice (WileyInterscience, New York, 1990)

5. A. Qazi, J. Quigley, A. Dickson, K. Kirytopoulos, Int. J. of Proj. Man. 34/7, 1183 (2016)

6. G. Ćwikła, App. Mech. and Mate. 474, 27 (2014)

7. K. Foit, Adv. Mater. Res. 837, 577 (2014)

8. H. A. Mesa, K. R. Molenaar, L. F. Alarcón, Int. J. of Pr. Man. 34/7, 1089 (2016)

9. E. Houghton, V. Portougal, Int. Trans. in Op. Res. 4/5-6, (1997)

10. http://www.directindustry.com/prod/caterpillar-global-mining/product-55229916883.html

11. A. Gwiazda, Adv. Mat. Res. 837, 393 (2014)

12. M. Bączkowicz, A. Gwiazda, IOP Conf. Ser.: Mater. Sci. Eng. 95 (2015)

13. S. Topolska, J. Łabanowski, Mat in Tech. 49/4, 481 (2015)

14. J. Łabanowski, A. Świerczyńska, S. Topolska, Pol. Mar. Res. 21/4, 108 (2014)

15. A. Grajcar, A. Płachcińska, S. Topolska, M. Kciuk, Mat in Tech. 49/6, 889 (2015)

16. I. Paprocka, W. Kempa, K. Kalinowski, C. Grabowik, IOP Conf. Ser.: Mater. Sci. Eng. 95, (2015)

17. W. Kempa, I. Paprocka, K. Kalinowski, C. Grabowik, Int. J. of Mod. Manuf. Technol. 7/2, 95 (2015)

18. G. Ćwikła, Adv. Mat. Res. 837, 618 (2014)

19. K. Foit, A. Gwiazda, W. Banaś, A. Sękala, P. Hryniewicz, IOP Conf. Ser. Mater. Sci. Eng. 95 (2015) 